\title{
Pancreatico-Pleural Fistula: A Rare Complication of Chronic Pancreatitis
}

\author{
Arya Ponnappan*, Jobin Kunjumon Vilapurathu, Anitta Shaji, Chriteena Mariyam Baby, \\ Diya Shibuchan
}

Department of Pharmacy Practice, Nirmala College of Pharmacy, Muvattupuzha, Kerala, INDIA.

\begin{abstract}
Pancreatico-pleural Fistula is rare complication of chronic pancreatitis and it occurs in considerably less number of patients. We present a case of left sided pleural effusion that was attributable to pancreatico-pleural fistula. A 30-year old alcoholic patient who had worsening dyspnea, hemoptysis and intractable cough. Diagnosis is difficult due to the prevalance of respiratory symptoms than symptoms due to pancreatitis. Diagnosis is concluded by the detection of high level of amylase and lipase in pleural fluid and by ERCP. It had been managed by placing a stent on main pancreatic duct at the site of leakage by ERCP along with giving octreotide for 7 days. The patient's symptoms was improved throughout hospitalization.
\end{abstract}

Key words: Pancreatico-pleural fistula, Chronic pancreatitis, Pleural effusion, Amylase, Lipase.

\section{INTRODUCTION}

Pancreatico-pleural Fistula (PPF) is an uncommon complication that occur in $0.4 \%$ of the patients with pancreatitis. Alcohol abuse is the most common cause of chronic pancreatitis leading to PPF and the other rare causes are gallstones, trauma, idiopathic pancreatitis and PD anomalies in pediatric patients. ${ }^{1}$ It is due to chronic pancreatic inflammation results in the disruption of main pancreatic duct which may leads to pancreatic secretion drainage into the pleural cavity. ${ }^{2}$ Pancreatic fistula may communicate with the peritoneal cavity, which leads to pancreatic ascites and with the pleural cavity, leads to the formation of pancreatico-pleural fistula. Patients typically present pulmonary symptom rather than symptoms related to pancreatitis which may leads to misdiagnosis and prolonged hospitalization. ${ }^{3,4}$ Here we present a case in which diagnosis was delayed due to absence of symptoms related to pancreatitis and was successfully treated through endoscopic procedure after failed conservative therapy.

\section{CASE PRESENTATION}

A 30-year old male patient with a past history of alcoholic pancreatitis who presented with worsening dyspnea, hemoptysis and intractable cough. He is a chronic alcoholic with a daily consumption of $100 \mathrm{gm} / \mathrm{dl}$. He was admitted to a local hospital with the complaints of severe abdominal pain and back pain 4 months ago and was administered analgesics and intravenous fluid and was managed conservatively. A couple of weeks later he was re-hospitalized for cough with dyspnea on exertion. CXR showed left side pleural effusion and an ICD drain was placed in the left chest. Pleural fluid evaluation demonstrated an exudative effusion with raised ADA level of $44 \mathrm{IU} / \mathrm{L}$, suggestive of tuberculosis pleural effusion and pathologically it was negative for malignancy and ATT was begun. Due to
DOI: 10.5530/ijopp.14.4.65

Address for correspondence: Dr. Arya Ponnappan, Pharm $D$,

Nirmala College of Pharmacy, Muvattupuzha-686661, Kerala, INDIA.

Phone no: +919744938205 Email id: aryaponnappan97@ gmail.com

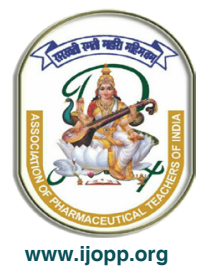


persisting cough and breathlessness, he was further referred to our hospital.

The patient came with the complaints of shortness of breath, chest pain, hemoptysis and cough. On physical exam, blood pressure 120/80 mmhg, heart rate of 70 beat per minute, respiratory rate of 18 breaths per minute, temperature $36.6^{\circ} \mathrm{C}$, oxygen saturation $98 \%$, the patient was alert and oriented.

The blood examination showed raised serum amylase level of $750 \mathrm{U} / \mathrm{L}$ and serum lipase of $285.83 \mathrm{U} / \mathrm{L}$, total cholesterol $213 \mathrm{mg} / \mathrm{dl}$, serum triglyceride $271 \mathrm{mg} / \mathrm{dl}$, LDL cholesterol $134 \mathrm{mg} / \mathrm{dl}$, CRP $217.4 \mathrm{mg} / \mathrm{L}$, SGOT 26 U/L, SGPT 24U/L. Subsequently, bronchoscopy with BAL was performed, smear and CBNAAT examination was done as the patient has no sputum and it was negative for PTB. The patient was underwent thoracoscopy and took biopsy. The pleural fluid analysis showed lipase of $117250 \mathrm{IU} / \mathrm{L}$ and amylase of $121500 \mathrm{IU} / \mathrm{L}$ which raised the suspicion of PPF. On biopsy blood clot and necrotic tissue was found and cytology report showed the presence of the inflammatory cell. Pleural fluid was quickly re-accumulating despite of the repeated aspiration, the pleural fluid was rapidly re-accumulating so chest tube was inserted. He was advised CEMRI and MRCP which could not performed due to incessant cough. CECT thorax, abdomen and pelvis showed the evidence of the exudative effusion in the left lower para mediastinal region and calcification in the head region of the pancreas.

The patient was kept NPO and given total parenteral nutrition followed by, treatment with octreotide $100 \mathrm{mg} \mathrm{s} / \mathrm{c}$ thrice daily was initiated for 7 days. The patient then underwent an endoscopic retrograde cholangiopancreatography (ERCP) for further diagnosis and visualization of pancreatic fistula. ERCP showed stricture in head region with upstream gross dilation of pancreatic duct. A $5 \mathrm{Fr} \times 7 \mathrm{~cm}$ single pigtail PD stent had been placed in the main pancreatic duct at the site of leakage. The pleural drainage from the tube reduced markedly after ERCP and stent placement. Subsequently, chest tube was removed on $8^{\text {th }}$ day after ERCP.

The patient's symptoms of shortness of breath, abdominal pain, cough improved throughout his hospitalization.

\section{DISCUSSION}

Pleural effusion due to pancratico-pleural fistula is a rare entity with a probable incidence rate of $0.4 \%$, while $3-7 \%$ of patients with pancreatitis can develop pleural effusion. PPF predominantly seen in males in their late 40s with pancreatitis due to excessive alcohol intake. Biliary stones, trauma and idiopathic pancreatitis may be the reason for PPF in relatively small percentage of population. ${ }^{5,6}$ Pleural effusion typically occur on the left side (42\%-67\%) but it can also occur on the right side (19\%-40\%) or both side (14\%-17\%). The evidence of recurrent, rapidly accumulating pleural effusion even after repeated thoracentesis or a history of pancreatitis raises the suspicion of pancreatico pleural fistula

The most common presenting complaints was dyspnea in $65 \%-75 \%$ cases while other common presenting complaints include chest pain, cough, abdominal pain and the less common complaints include fever, weight loss and hemoptysis. ${ }^{1}$

Diagnosis may be delayed due to the predominance of pulmonary symptoms such as shortness of breath, cough and chest pain secondary to pleural effusion. The initial step in the diagnosis of PPF is the determination of pleural amylase level. The pleural amylase level of above $50000 \mathrm{U} / \mathrm{L}$ highly suggestive of PPF. Once it is confirmed, next step is the visualization of the fistula. CT, ERCP and MRCP are commonly used in current practice and the sensitivity of these modalities may be $47 \%, 78 \%$ and $80 \%$ respectively.

CT of the thorax and abdomen has been helpful in identifying fistula and in providing evidence of pancreatic atrophy, pancreatic duct dilation, calcification and pseudocysts. CT scan performed immediately after ERCP has greater sensitivity in detecting the fistula as it involve the use of contrast that injected into the PD. ${ }^{7}$ ERCP is helpful in both diagnosis and management of pancreatico-pleural fistula. It will reveal the site of leak as well as ductal morphology. ${ }^{5}$ In our patient, the diagnosis was confirmed with ERCP and was managed by placing stent in the MPD at the site of leakage. The condition of the patient improved dramatically which showed the effectiveness of the procedure. ERCP has certain disadvantages; it is an invasive procedure, unable to clearly demonstrate a fistula beyond strictures and it has the risk of potentially life threatening complications such as infection, bleeding and perforation. Now a days MRCP is the most widely used imaging modality as it is non-invasive and its ability to visualize a fistula beyond strictures. ${ }^{1}$

The management PPF can be divided into conservative and surgical. Conservative management include medical and endoscopic therapies. Medical treatment with octreotide helps to decrease pancreatic secretion followed by total parenteral nutrition. Usually it requires 2-3 weeks 
of medical treatment along with chest tube drainage for the recurrent pleural effusion. However failed medical treatment leads to higher rate of complications include malnutrition, central catheter infection and sepsis.

Endoscopic stenting has minimum morbidity and mortality which has been reported to be an effective therapeutic option. The period of hospitalization can be shortened when it is used in combination of octreotide. Surgical treatment is the last resort when all other treatment fail and its advantages include low morbidity and mortality, quicker recovery and better outcome than other treatment options..$^{1-3}$

\section{CONCLUSION}

In conclusion, PPF is a rare complication of chronic pancreatitis. The evidence of high level of amylase in pleural fluid is the key in determining the condition. The differential diagnosis should be assesses according to the clinical symptoms and further imaging of pancreas and thoracic cavity. ERCP find helpful in both diagnosis and treatment of PPF.

\section{ACKNOWLEDGEMENT}

We are thankful to Management, Pharmacy practice department and Principal of our college for providing necessary facilities and support.

\section{CONFLICT OF INTEREST}

The authors declare that there is no conflict of interest.

\section{ABBREVIATIONS}

PPF: Pancreatico-pleural fistula; PD: Pancreatic duct; CXR: Chest X-ray; ADA: Adenosine deaminase; ATT: Anti-tubercular therapy; ICD: intercostal drainage CT: Computed tomography; MRCP: Magnetic resonance Cholangiopancreatography; ERCP: Endoscopic Retrograde Cholangiopancreatography; MPD: Main Pancreatic Duct; NPO: Nil per orally.

\section{REFERENCES}

1. Tay CM, Chang SK. Diagnosis and management of pancreaticopleural fistula. Singapore Med J. 2013;54(4):190-4. doi: 10.11622/smedj.2013071, PMID 23624444.

2. Cazzo E, Apodaca-Rueda M, Gestic MA, Chaim FHM, Saito HPA, Utrini MP, et al. Management of pancreaticopleural fistulas secondary to chronic pancreatitis. Arq Bras Cir Dig. 2017;30(3):225-8. doi: 10.1590/01026720201700030014 , PMID 29019567.

3. Ramahi A, Aburayyan KM, Said Ahmed TS, Rohit V, Taleb M. Pancreaticopleural fistula: A rare presentation and a rare complication. Cureus. 2019;11(6):e4984. doi: 10.7759/cureus.4984, PMID 31501720.

4. Zhang JY, Deng ZH, Gong B. Pancreaticopleural fistula in children with chronic pancreatitis: A case report and literature review. BMC Pediatr. 2020;20(1):274. doi: 10.1186/s12887-020-02174-x, PMID 32493299.

5. Bediwy AS. Pancreatico-pleural fistula: A rare cause of massive right-sided pleural effusion. Egypt J Chest Dis Tuberc. 2015;64(1):149-51. doi: 10.1016/j. ejcdt.2014.08.004

6. Kord Valeshabad A, Acostamadiedo J, Xiao L, Mar W, Xie KL. Pancreaticopleural fistula: A review of imaging diagnosis and early endoscopic intervention. Case Rep Gastrointest Med. 2018;2018:7589451. doi: 10.1155/2018/7589451, PMID 30210880.

7. Bustamante Bernal MA, Gonzalez Martinez JL, Ortiz A, Zuckerman MJ. Recurrent pleural effusion secondary to a pancreatic-pleural fistula treated endoscopically. Am J Case Rep. 2017;18(18):750-3. doi: 10.12659/ajcr.903925, PMID 28676624. 